\title{
Contribuição ao zoneamento agrossilvipastoril com base na perda de solo e balanço hídrico climatológico
}

\author{
Contribution to agrosilvopastoral zoning based on soil loss and climatological water balance \\ Contribución a la zonificación del agrosilvipastoril en base a la pérdida de suelo y el balance \\ hídrico climático
}

Recebido: 24/06/2021 | Revisado: 30/06/2021 | Aceito: 02/07/2021 | Publicado: 14/07/2021

\author{
Fernanda Dias dos Santos \\ ORCID: https://orcid.org/0000-0002-6337-3061 \\ Universidade Federal de Santa Maria, Brasil \\ E-mail: fernandadiotti@hotmail.com \\ Jussara Cabral Cruz \\ ORCID: https://orcid.org/ 0000-0002-0901-1254 \\ Universidade Federal de Santa Maria, Brasil \\ E-mail: jussaracruz@gmail.com \\ Alexandre Swarowsky \\ ORCID: https://orcid.org 0000-0002-0787-2691 \\ Universidade Federal de Santa Maria, Brasil \\ E-mail: aleswar@gmail.com \\ Elenice Broetto Weiler \\ ORCID: https://orcid.org/0000-0003-3389-4234 \\ Universidade Federal de Santa Maria, Brasil \\ E-mail: elenice.bere@hotmail.com \\ Roberta Aparecida Fantinel \\ ORCID: https://orcid.org/0000-0002-1827-7943 \\ Universidade Federal de Santa Maria, Brasil \\ E-mail: fantinel.ar@gmail.com \\ Camila Andrzejewski \\ ORCID: https://orcid.org/0000-0001-8316-2483 \\ SULCLEAN Serviços Integrados LTDA, Brasil \\ E-mail: camila_andrzejewski@hotmail.com \\ Keila Fernanda Hedlund Ferrari \\ ORCID: https://orcid.org/ 0000-0002-8695-6892 \\ Universidade Federal de Santa Maria, Brasil \\ E-mail: keilahedlund@hotmail.com
}

\begin{abstract}
Resumo
O planejamento ambiental é um instrumento para a gestão de bacias hidrográficas, permitindo suporte ao processo de tomada de decisões. A pesquisa teve por objetivo criar subsídios para tomada de decisão no planejamento ambiental do uso do solo da Bacia Hidrográfica Cachoeira Cinco Veados, RS. Com base no cruzamento das variáveis de perda potencial de solo (EUPS) e do balanço hídrico climatológico (BHC), obtiveram-se as classes de fragilidades para três cenários de chuvas com um limite de perda de solo pré-estabelecido. As classes mais frágeis são encontradas nas maiores classes de perda de solo e nas classes mínimas do balanço hídrico climatológico. Esses resultados nos permitem concluir a importância do planejamento ambiental continuado na Bacia, pois mesmo para cenários de perdas de solo mínimas, $1,02 \%$ da área $\left(15,81 \mathrm{~km}^{2}\right)$ não são permitidos de uso de acordo com os critérios adotados, ou seja, essas áreas apresentam perdas afora do limite estabelecido.
\end{abstract}

Palavras-chave: Erosão hídrica; Balanço hídrico; Planejamento; Meio ambiente; Usos do solo.

\begin{abstract}
Environmental planning is an instrument for watershed management, enabling support for the decision-making process. The research aimed to create subsidies for decision making in the environmental planning of the land use of the Cachoeira Cinco Veados River Basin, RS. Based on the crossing of the potential soil loss (EUPS) and climatic water balance (BHC) variables, fragility classes were obtained for three rainfall scenarios with a pre-established soil loss limit. The most fragile classes are found in the largest classes of soil loss and in the minimal classes of climatological water balance. These results allow us to conclude the importance of continued environmental planning in the Basin, because even for minimal soil loss scenarios, $1.02 \%$ of the area $\left(15.81 \mathrm{~km}^{2}\right)$ is not allowed to be used according to the adopted criteria, that is, these areas show losses beyond the established limit.
\end{abstract}

Keywords: Water erosion; Water balance; Planning; Environment; Soil use. 


\section{Resumen}

La planificación ambiental es un instrumento para la gestión de las cuencas hidrográficas, que permite apoyar el proceso de toma de decisiones. La investigación tuvo como objetivo crear subsidios para la toma de decisiones en la planificación ambiental del uso del suelo en la Cuenca Cachoeira Cinco Veados, RS. A partir del cruce de las variables de pérdida potencial de suelo (EUPS) y balance climatológico hídrico (BHC), se obtuvieron las clases de fragilidad para tres escenarios de precipitación con un límite de pérdida de suelo preestablecido. Las clases más frágiles se encuentran en las clases más grandes de pérdida de suelo y en las clases mínimas del balance hídrico climatológico. Estos resultados permiten concluir la importancia de la planificación ambiental continua en la Cuenca, ya que incluso para escenarios de mínima pérdida de suelo, el $1.02 \%$ del área $\left(15.81 \mathrm{~km}^{2}\right)$ no está permitido para el uso de acuerdo con los criterios adoptados, es decir, estas áreas. mostrar pérdidas más allá del límite establecido.

Palabras clave: Erosión del agua; Balance hídrico; Planificación; Medio ambiente; Uso de la tierra.

\section{Introdução}

A falta de planejamento e o uso não sustentável dos recursos naturais contribui para a degradação ambiental dos ecossistemas. Estima-se que o mundo já perdeu, desde a metade do Século XX, 1/5 da superfície cultivável e aproximadamente $20 \%$ das florestas tropicais. Além disso, a cada ano desaparecem cerca de 25 bilhões de toneladas de húmus por efeito da erosão, desertificação, salinização e outros processos de degradação ambiental (Dos Santos Andrade et al., 2018; De Faria, 2010).

O planejamento ambiental de uso do solo, o controle de processos erosivos e a minimização de impactos ao ambiente, principalmente aos corpos hídricos, configuram uma estratégia para o entendimento dos processos do ambiente, pois ao compreender sua vulnerabilidade, menos suscetível ele estará à impactos ambientais. Daí a importância de estudos integrados do ambiente físico-ambiental em bacias hidrográficas (Costa et al., 2019; Pereira \& De Cristo, 2019), como fonte de compreensão para o entendimento da elaboração de projetos de caráter preventivo e interdisciplinar para a elaboração de cenários futuros (Ribeiro \& Albuquerque, 2017).

Vários podem ser os critérios passíveis de subsidiar estudos de planejamento ambiental, como recorte territorial, legislação vigente, componentes físico-biótico. Dentre as variáveis utilizadas, está a estimativa da perda potencial de solo (PPS), calculada pela Equação Universal de Perda de Solo - EUPS (Wischmeier \& Smith, 1978), que pode ser espacializada em bacias hidrográficas, por exemplo, na estratégia proposta por Weiler (2017), desenvolvida para auxiliar na gestão e zoneamento da cobertura do solo. Outra variável amplamente utilizada, nas suas mais diversas modalidades, é o balanço hídrico climatológico - BHC (Thornthwaite \& Mather, 1955), que possibilita o monitoramento da variação do armazenamento de água no solo.

Assim, o trabalho apresenta uma proposta de utilização da EUPS combinada com BHC com objetivo de subsidiar estudos de planejamento ambiental do uso do solo, utilizando como estudo de caso a Bacia Hidrográfica Cachoeira Cinco Veados, RS.

\section{Metodologia}

A Bacia Hidrográfica Cachoeira Cinco Veados está localizada na Bacia Hidrográfica do Rio Ibicuí, Estado do Rio Grande do Sul (Figura 1), entre as coordenadas geográficas $28^{\circ} 53^{\prime}$ e $30^{\circ} 51^{\prime}$ de latitude Sul e 533' e $57^{\circ} 36^{\prime}$ de longitude Oeste. Abrange os municípios de Tupanciretã, Quevedos, Júlio de Castilhos e São Martinho da Serra, com área de drenagem de 1541,9 $\mathrm{Km}^{2}$. 
Figura 1: Localização da Bacia Hidrográfica Cachoeira Cinco Veados, RS.

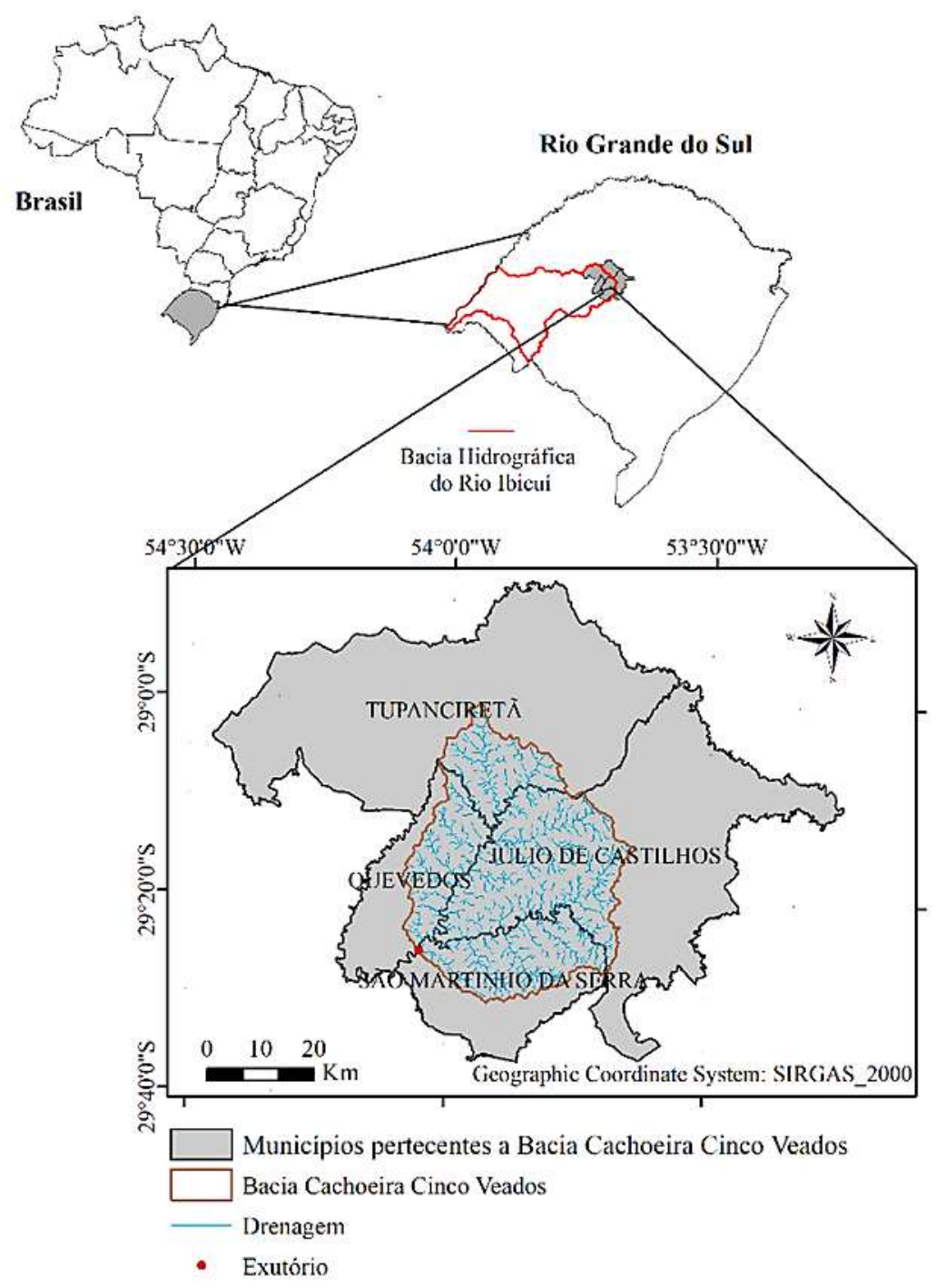

Fonte: Autores (2021).

Quanto a natureza do trabalho, o mesmo é de cunho qualitativo (Pereira et al., 2008) e como base metodologias propostas por Thornthwaite e Mather (1955), Wischmeier e Smith (1978), Carvalho Neto (2011) e Weiler (2017), utilizadas a fim de embasar o planejamento ambiental de bacias hidrográficas.

Para o planejamento ambiental do uso do solo na bacia estudada, foram elaborados mapas de fragilidades, onde se considera valores relativos em função do zoneamento agrossilvipastoril. Desta forma, foram usados dois critérios: PPS e BHC, os quais foram divididos em classes. Posteriormente, foi realizado o cruzamento dos dados, determinando-se assim as áreas de criticidade de uso do solo para a bacia.

A elaboração dos mapas de PPS foi determinada por meio da Equação 1, baseado em Wischmeier e Smith (1978). A utilização da EUPS no presente trabalho deu-se devido ao tamanho da área a ser estudada, onde o método estima as perdas de solo em função do uso, visando auxiliar no zoneamento agrossilvipastoril.

$$
\mathrm{A}=\mathrm{R} \text { K L S C P }
$$

Onde:

A = representa a estimativa de perda média anual de solo em determinada área, em condições específicas de uso e ocupação do solo $\left(\right.$ t.ha ${ }^{-1} \cdot$ ano $\left.^{-1}\right)$; 
$\mathrm{R}=$ Erosividade da chuva $\left(\mathrm{MJ}_{\mathrm{N}} \mathrm{ha}^{-1} \cdot \mathrm{mm} \mathrm{h}^{-1} \cdot \mathrm{ano}^{-1}\right)$;

$\mathrm{K}=$ Erodibilidade do solo $\left(\mathrm{t} . \mathrm{MJ}^{-1} \cdot \mathrm{mm}^{-1} \cdot \mathrm{h}^{-1}\right)$;

$\mathrm{L}=$ Comprimento de rampa - relação de perdas de solo entre um comprimento de declive qualquer e um comprimento de rampa de 22,10 metros para o mesmo solo e grau de declividade;

$\mathrm{S}=$ Declividade de rampa (\%) - relação de perdas de solo de um declive qualquer e um declive de $9 \%$ para o mesmo comprimento de rampa;

$\mathrm{C}=$ Uso e manejo do solo ( $(0$ a 1$)$ - relação entre perdas de solo de um terreno cultivado em dadas condições e as perdas correspondentes de um terreno mantido continuamente descoberto, ou seja, nas mesmas condições em que o Fator K é avaliado;

$\mathrm{P}=$ Práticas conservacionistas ( 0 a 1 ) - representa os efeitos das práticas conservacionistas como plantio em nível, terraceamento e plantio em faixas na erosão do solo, expressando a relação entre a perda de solo com determinada prática conservacionista e a correspondente perda quando a cultura está implantada no sentido do declive (morro abaixo).

Cada fator foi calculado como descrito em Weiler (2017), com exceção do fator C, função do uso do solo. Para este, foram criados diferentes cenários de uso e cobertura do solo, baseados no uso atual da bacia, onde no Cenário 1 toda a área da bacia é coberta por Soja/Pastagem/Soja, no Cenário 2, pelo uso Campestre e no Cenário 3, pelo uso Floresta/Reflorestamento. Para ambos os cenários o uso antrópico urbano permanece inalterado.

Para o cálculo da erosividade da chuva, foram utilizadas séries históricas de precipitação de 10 estações pluviométricas obtidas junto à ANA, referente ao período de 1985-2015. A perda potencial de solo foi gerada multiplicando-se os fatores da EUPS, com auxílio do software ArcGIS, versão 10.5, e categorizada em sete classes de perdas para fins de planejamento (0 $10 ; 10-50 ; 50-100 ; 100-500 ; 500-1.000 ; 1000-5.000 \mathrm{e}>5.000$ ton.ha $^{-1} \cdot$ ano $^{-1}$ ).

O mapa final de PPS para a Bacia Cachoeira Cinco Veados, RS, foi resultado do cruzamento dos 3 mapas de cenários: campestre, floresta/reflorestamento e soja/pastagem/soja. A partir da análise das perdas potenciais, é que se projetam as sugestões para revisão do uso do solo no processo de planejamento.

Adotou-se como limite pré-estabelecido 100 ton.ha ${ }^{-1} \cdot$ ano $^{-1}$ de perdas potenciais de solo, assim a título de exemplificação nestas áreas não haverá necessidade de mudanças para os usos. Já para perdas potenciais acima deste limite, a área passa a estar submetida a estudos de planejamento com sugestões de outros usos mais protetivos, ou seja, passando a ser área de planejamento de uso do solo.

Para BHC, os mapas foram elaborados fundamentando-se no trabalho desenvolvido por Carvalho Neto (2011), apontando áreas de criticidade relacionadas à disponibilidade hídrica e visando minimizar perdas por déficit hídrico, considerando as chuvas mensais mínimas, médias e máximas.

O BHC foi calculado pelo método de Thornthwaite e Mather (1955), conforme a Equação 2.

\section{$\mathrm{BHC}=\mathrm{CAD} * \mathrm{PREC} * \mathrm{ETP}$}

Onde:

BHC = Balanço hídrico climatológico;

$\mathrm{CAD}=$ capacidade de água disponível, fator dependente do uso e tipo de solo;

$\mathrm{PREC}=$ precipitação;

ETP = evapotranspiração.

Foi calculado um BHC mensal, utilizando as precipitações médias, máximas e mínimas, com base nas séries históricas de precipitação, evapotranspiração e temperatura referente ao período de 1985-2015 e dados de uso e tipo de solo. O BHC foi gerado por meio do algoritmo em linguagem PythonTM (Python Software Foundation, 2017) utilizando o package ArcPy®, no software ArcGIS, versão 10.5.

Em função da distribuição das chuvas, o resultado do BHC foi dividido em três classes $(<0 \mathrm{~mm}$; entre 0 e $5 \mathrm{~mm}$ e $>5$ 
$\mathrm{mm}$ ). Quando os valores se encontram abaixo de zero, indica que há déficit hídrico para o local, assim como os valores que se encontram entre 0 e $5 \mathrm{~mm}$ indicam que, em situações específicas de culturas, as mesmas devem ser irrigadas e para valores acima de $5 \mathrm{~mm}$, o balanço hídrico climatológico já atende à demanda de água da maioria das culturas.

Para criação dos mapas de fragilidades, realizou-se o cruzamento destes dados, multiplicando-se os mapas PPS e BHC, conforme Figura 2.

Figura 2: Fluxograma de elaboração dos mapas para planejamento ambiental da Bacia Cachoeira Cinco Veados, RS.

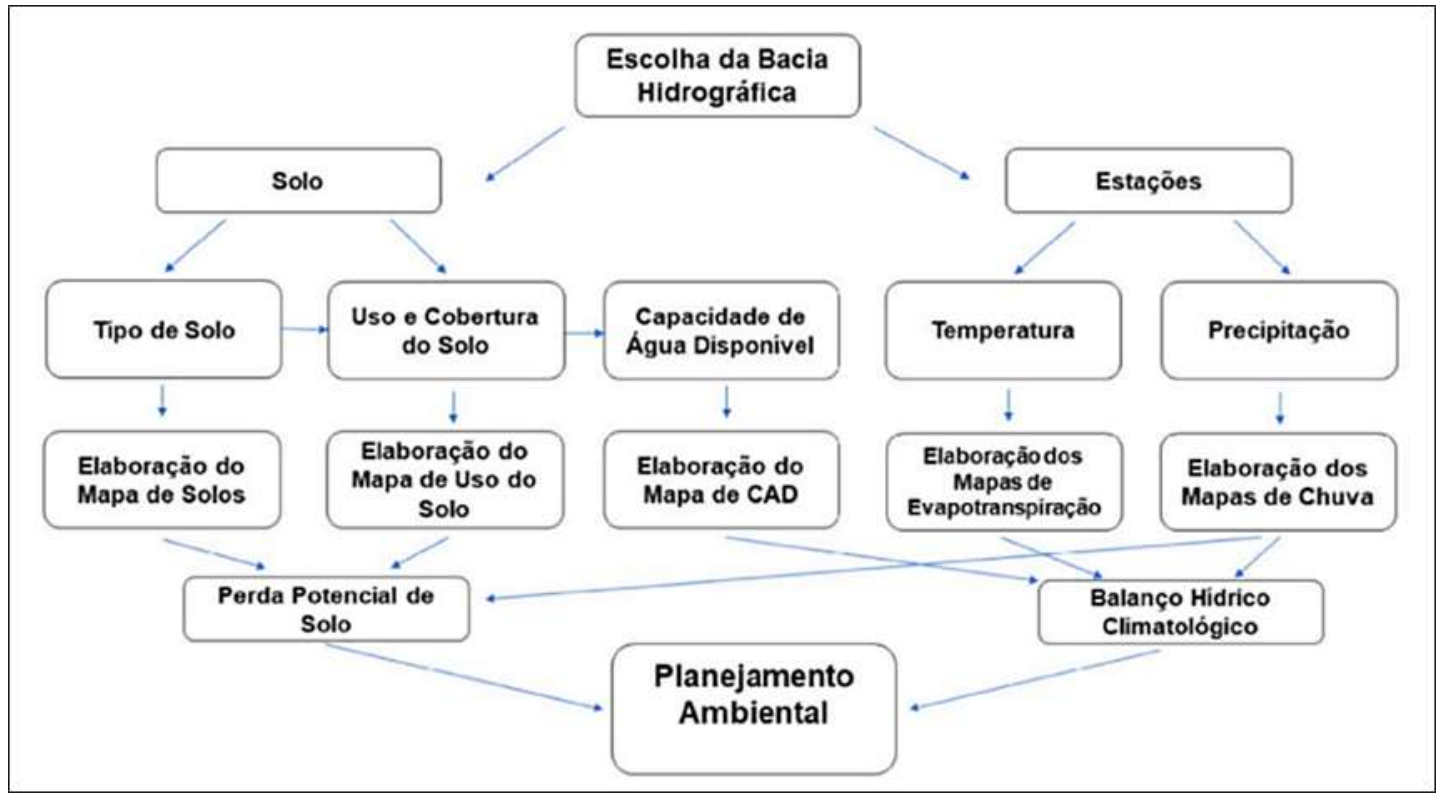

Fonte: Autores (2021).

Deste cruzamento atribuiu-se a cada combinação de classes um valor de fragilidade, sendo que as classes indicam que, à medida que aumenta o valor de fragilidade, diminui a criticidade, ou seja, o valor 1 representa a maior criticidade e o valor 21 a menor criticidade (Tabela 1).

Tabela 1: Classes de Fragilidade para a Bacia Cachoeira Cinco Veados, RS.

\begin{tabular}{|c|c|c|c|}
\hline \multirow{2}{*}{\begin{tabular}{l}
\multicolumn{1}{c}{ Fragilidade } \\
Perda Potencial de Solo \\
$\left(\right.$ ton.ha $^{-1}$.ano \\
\end{tabular}} & \multicolumn{3}{|c|}{ BHC (mm) } \\
\hline & $<0$ & $0-5$ & $>5$ \\
\hline Classe A (0-10) & 7 & 14 & $21 * *$ \\
\hline Classe B (10-50) & 6 & 13 & 20 \\
\hline Classe C (50-100) & 5 & 12 & 19 \\
\hline Classe D (100-500) & 4 & 11 & 18 \\
\hline Classe E (500-1.000) & 3 & 10 & 17 \\
\hline Classe F (1.000-5.000) & 2 & 9 & 16 \\
\hline Classe G (>5.000) & $1 *$ & 8 & 15 \\
\hline
\end{tabular}

Fonte: Autores (2021).

Para classes acima de 100 ton/ha de perda potencial de solo sugerem-se culturas ou práticas conservacionistas menos errodíveis (Weiler, 2017). Nas classes de fragilidade 1, 2 e 3, deve-se atentar para o BHC, ou seja, priorizar práticas que elevem a capacidade de água disponível (CAD), visto que são as 3 classes mais críticas em relação as condições de déficit hídrico. 


\section{Resultados e Discussão}

O cenário de uso final de PPS para a bacia estudo de caso Cachoeira Cinco Veados, foi obtido do cruzamento entre os diferentes cenários de uso único, considerando as perdas de solo toleráveis até a classe de 100 ton.ha $^{-1}$.ano ${ }^{-1}$, conforme estudo desenvolvido por Weiler (2017).

Aplicando a metodologia da equação 1 no cenário com uso único campestre, os resultados indicaram que cerca de 1.070,6 km² estão de acordo com o critério de perda de solo tolerável sugerido por Weiler (2017). As demais áreas necessitam de planejamento com outros usos do solo menos degradantes, pois as perdas estão acima do limite estabelecido, em 30,6\% da área da bacia.

Para planejamento do uso do solo nas áreas que indicaram perdas maiores que o limite estabelecido, pode-se estudar outros usos. Por exemplo, na sequência, utiliza-se a cobertura imediatamente mais protetiva do solo: floresta/reflorestamento. Conforme o processamento, a bacia comporta uma área para esse uso correspondente a 94,66\% $\left(1.459,6 \mathrm{~km}^{2}\right)$ da área total, atingindo valores em torno de $40 \%$ inferiores à perda quando o uso é campestre.

Já o cenário com uso Soja/Pastagem/Soja, considerando a adoção de práticas conservacionistas na bacia, indica que $1,02 \%\left(15,8 \mathrm{~km}^{2}\right)$ de toda a área da Bacia não admite o uso para esta cobertura de solo, ou seja, em $1.526,1 \mathrm{~km}^{2}$ podem ser manejados com o uso da cultura de soja no verão e pastagem no inverno. A PPS para este uso foi de 600,8 ton.ha $^{-1}$. ano ${ }^{-1}$, apresentando menor potencial erosivo do que os demais usos. Em comparação, por exemplo, com o cenário campestre, este dado pode ser explicado em função da agricultura apresentar práticas de manejo e melhoramento genético associados, fazendo com que tenha maior biomassa e assim, maior recobrimento da superfície (Guimarães et al., 2017; Wolschick et al., 2016).

Após a reclassificação dos usos do solo, determinados em função dos usos atuais da bacia, de acordo com cada cobertura, obteve-se o mapa geral de planejamento ambiental de uso do solo (Figura 3). Para áreas impróprias para uso campestre, foi indicado o uso floresta/reflorestamento e as que restaram ainda impróprias segundo o critério adotado de perdas, indica-se o uso soja/pastagem/soja.

Figura 3: Mapa de planejamento da Bacia Cachoeira Cinco Veados, RS.

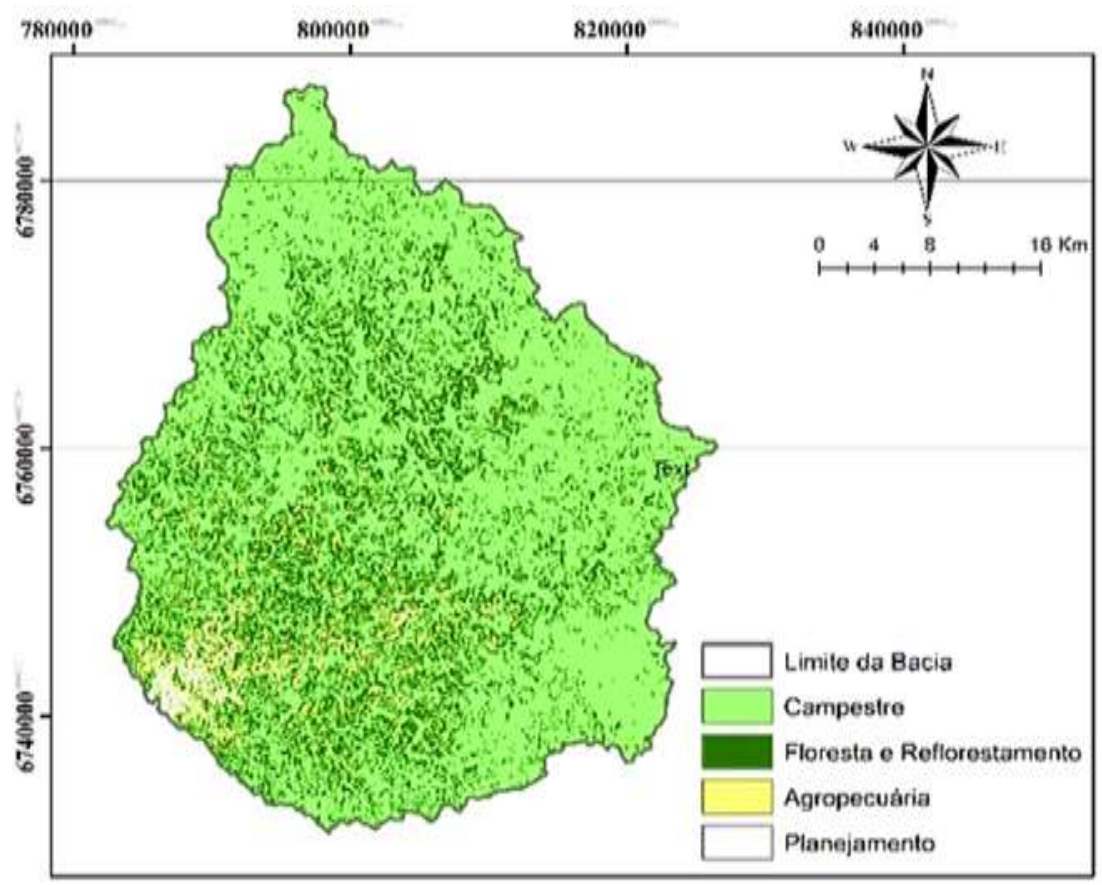

Fonte: Autores (2021). 
O planejamento considera que, respeitando o critério de limite máximo de PPS, cada área é passível de ser utilizada com o uso mapeado, mas também de qualquer outro uso que tenha menor potencial erodível, ou seja, um "C" menor. Dessa forma, os planejadores, empreendedores ou mesmo gestores, possuem uma referência para considerar em tomadas de decisão quanto aos usos, e quais as possíveis áreas com necessidades de estudos mais detalhados visando minimização de perdas de solo por erosão.

O cenário de planejamento, apesar de ser fundamentado no uso de solo que acarreta em perdas mínimas, ainda assim necessita de atenção em algumas áreas. Na Tabela 2 está apresentada a área por classe de PPS e na Figura 4 o mapa com espacialização das classes na área, sendo a Classe $3\left(10-50\right.$ ton.ha $^{-1} \cdot$ ano $\left.^{-1}\right)$ a que representa maior área de perda $(59,52 \%) \mathrm{em}$ relação a área total da Bacia.

Tabela 2: Área total por classe de perda potencial de solo para a Bacia Cachoeira Cinco Veados, RS.

\begin{tabular}{|c|c|c|}
\hline Classe de Perda (ton.ha ${ }^{-1}$ ano $^{-1}$ ) & Área $\left.\left(K^{2}\right)^{2}\right)$ & Área (\%) \\
\hline $1(0-10)$ & 130.03 & 8.43 \\
\hline $2(10-50)$ & 179.87 & 11.67 \\
\hline $3(50-100)$ & 917.71 & 59.52 \\
\hline $4(100-500)$ & 231.98 & 15.05 \\
\hline $5(500-1.000)$ & 80.29 & 5.21 \\
\hline $6(1.000-5.000)$ & 1.7 & 0.11 \\
\hline $7(>5.000)$ & 0.17 & 0.01 \\
\hline
\end{tabular}

Fonte: Autores (2021).

Figura 4: Mapas por classes de perda potencial de solo do cenário planejamento para a Bacia Cachoeira Cinco Veados, RS.

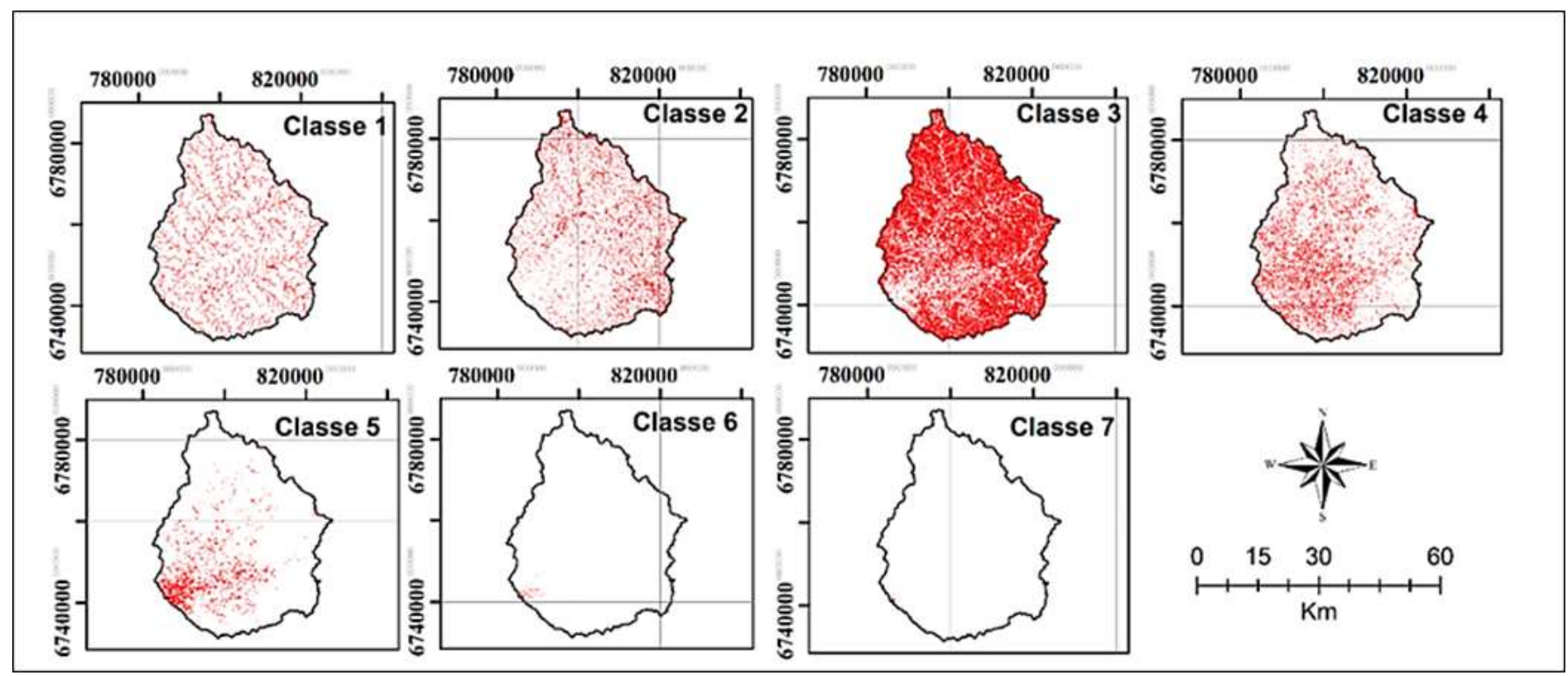

Fonte: Autores (2021).

Observa-se que, mesmo trabalhando com cenários que priorizem PPS mínima, ainda 15,81 km² não são passíveis de uso, em função do limite estabelecido de perda, demandando um planejamento de uso do solo detalhado e pontual para estas áreas, por estarem próxima ao exutório da bacia e apresentarem relevo íngreme, associado ao tipo de solo (Chernossolo) (pinheiro et al., 2020; saraiva et al, 2016). Esta situação indica que para estas áreas, o planejamento deve estar associado à conservação, 
podendo ser criadas áreas de proteção ambiental, unidades de conservação, preservadas e associadas aos projetos de pagamento de serviços ambientais.

A Bacia Cachoeira Cinco Veados, RS, mesmo estando inserida no Bioma Pampa, possui algumas características de região serrana, e isso deve ser levado em consideração quando se faz um planejamento ambiental de uso do solo, diretamente influenciado pelo relevo local (ceconi et al., 2018).

A segunda variável de planejamento de uso do solo foi a aplicação do método BHC espacializado, considerando o cenário de anos secos, normais e chuvosos, para o uso atual do solo. Trabalhou-se especificamente com o mês de janeiro, em função de ser o mês que apresentou a menor média mensal para o BHC, chegando a atingir, para anos secos (considerados anos com chuvas mínimas), valores negativos.

Dividiu-se o BHC em três classes: mínimo (chuvas mínimas), médio (chuvas normais) e máximo (chuvas máximas) (Figura 5). A classe 1 aponta maior criticidade para o estudo de caso e a classe 3 aponta menor criticidade.

Figura 5: Mapas por classes do balanço hídrico climatológico $(\mathrm{mm})$ do cenário planejamento para a Bacia Cachoeira Cinco Veados, RS.
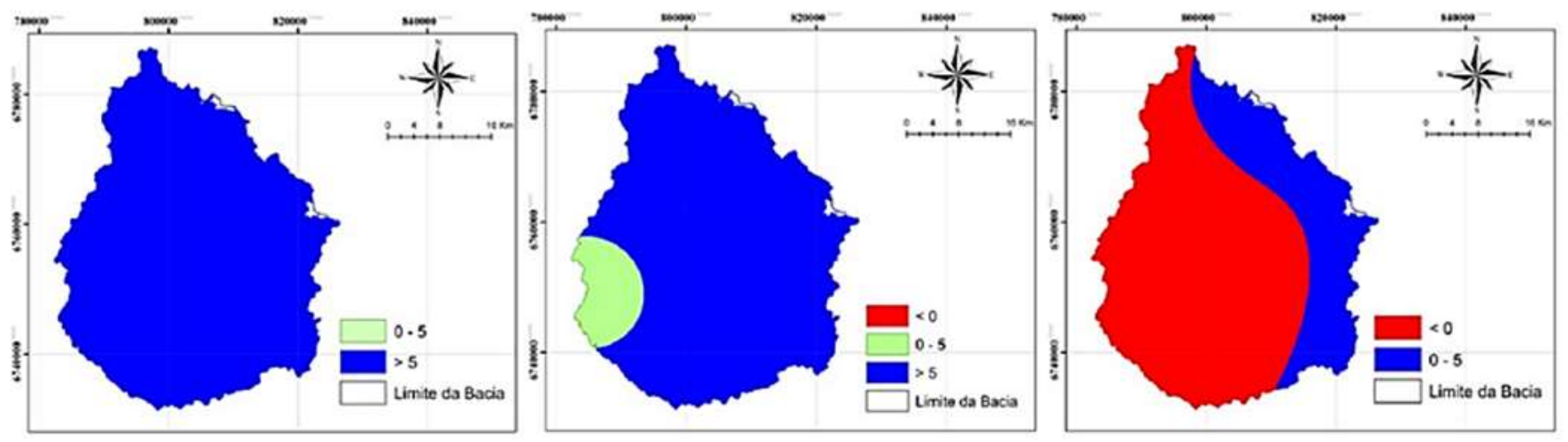

Fonte: Autores (2021).

Foram elaborados 3 mapas de planejamento ambiental de uso do solo: cruzamento dos dados de PPS e BHC considerando chuvas mínimas; cruzamento dos dados de PPS e BHC considerando chuvas médias e cruzamento dos dados de PPS e BHC considerando chuvas máximas.

Para PPS, utilizou-se o mapa de perdas gerado em função do planejamento definido de uso do solo, cujas áreas encontram-se dentro do limite de perda potencial definido por Weiler (2017). Para o processamento dos mapas, se considerou que a criticidade à erosão e ao déficit hídrico, analisados conjuntamente, diminui à medida que aumenta a classe de fragilidade.

O primeiro cenário de planejamento de uso do solo foi gerado multiplicando-se 7 classes de PPS e 3 classes do BHC, sendo que a classe de fragilidade que representa menor criticidade para a Bacia está definida pelo número 14. Na Tabela 3 verifica-se o tamanho da área abrangida por classe de fragilidade e o percentual representativo para a área total da Bacia para cada um dos 3 cenários estudados. 
Tabela 3: Área da Bacia por Classe de Fragilidade (USLE e BHC) para os 3 cenários estudados.

\begin{tabular}{|c|c|c|c|c|c|c|c|c|}
\hline \multicolumn{3}{|c|}{ Cenário 1} & \multicolumn{3}{|c|}{ Cenário 2} & \multicolumn{3}{|c|}{ Cenário 3} \\
\hline \multicolumn{3}{|c|}{$\begin{array}{c}\text { Perda Potencial de Solo X BHC } \\
\text { (Mín.) }\end{array}$} & \multicolumn{3}{|c|}{$\begin{array}{c}\text { Perda Potencial de Solo X BHC } \\
\text { (Méd.) }\end{array}$} & \multicolumn{3}{|c|}{$\begin{array}{c}\text { Perda Potencial de Solo X BHC } \\
\text { (Máx.) }\end{array}$} \\
\hline $\begin{array}{c}\text { Classe de } \\
\text { Fragilidade }\end{array}$ & $\begin{array}{c}\text { Área } \\
\text { (Hectare) }\end{array}$ & $\begin{array}{l}\text { Área } \\
(\%)\end{array}$ & $\begin{array}{c}\text { Classe de } \\
\text { Fragilidade }\end{array}$ & $\begin{array}{c}\text { Área } \\
\text { (Hectare) }\end{array}$ & $\begin{array}{c}\text { Área } \\
(\%)\end{array}$ & $\begin{array}{c}\text { Classe de } \\
\text { Fragilidade }\end{array}$ & $\begin{array}{c}\text { Área } \\
\text { (Hectare) }\end{array}$ & $\begin{array}{c}\text { Área } \\
(\%)\end{array}$ \\
\hline 1 & 9.161 & 5.9 & 5 & 1.119 & 0.7 & 12 & 12.804 & 8.3 \\
\hline 2 & 3.643 & 2.4 & 8 & 11.685 & 7.5 & 15 & 17.916 & 11.6 \\
\hline 3 & 10.646 & 6.9 & 9 & 757 & 0.5 & 16 & 1 & 0.001 \\
\hline 4 & 7.270 & 4.7 & 10 & 17.159 & 11.1 & 17 & 91.437 & 59.0 \\
\hline 5 & 61.785 & 39.9 & 11 & 1 & 0.001 & 18 & 23.033 & 14.9 \\
\hline 6 & 29.653 & 19.1 & 12 & 5.221 & 3.4 & 19 & 7.996 & 5.2 \\
\hline 7 & 20.330 & 13.1 & 13 & 86.016 & 55.5 & 20 & 190 & 0.1 \\
\hline 10 & 2.703 & 1.7 & 14 & 3.145 & 2.0 & 21 & 17 & 0.01 \\
\hline 11 & 7.863 & 5.1 & 15 & 2.510 & 1.6 & - & - & - \\
\hline 12 & 133 & 0.1 & 16 & 19.888 & 12.8 & - & - & - \\
\hline 13 & 190 & 0.1 & 17 & 151 & 0.1 & - & - & - \\
\hline 14 & 17 & 0.01 & 18 & 5.486 & 3.5 & - & - & - \\
\hline- & - & - & 19 & 15 & 0.01 & - & - & - \\
\hline- & - & - & 20 & 39 & 0.03 & - & - & - \\
\hline- & - & - & 21 & 2 & 0.001 & - & - & - \\
\hline
\end{tabular}

Fonte: Autores (2021).

Na Figura 6 está apresentado o Planejamento Ambiental de uso do solo considerando anos secos, com 12 classes de fragilidade.

Figura 6: Planejamento Ambiental da Bacia Cachoeira Cinco Veados, RS, considerando Perda Potencial de Solo e BHC.
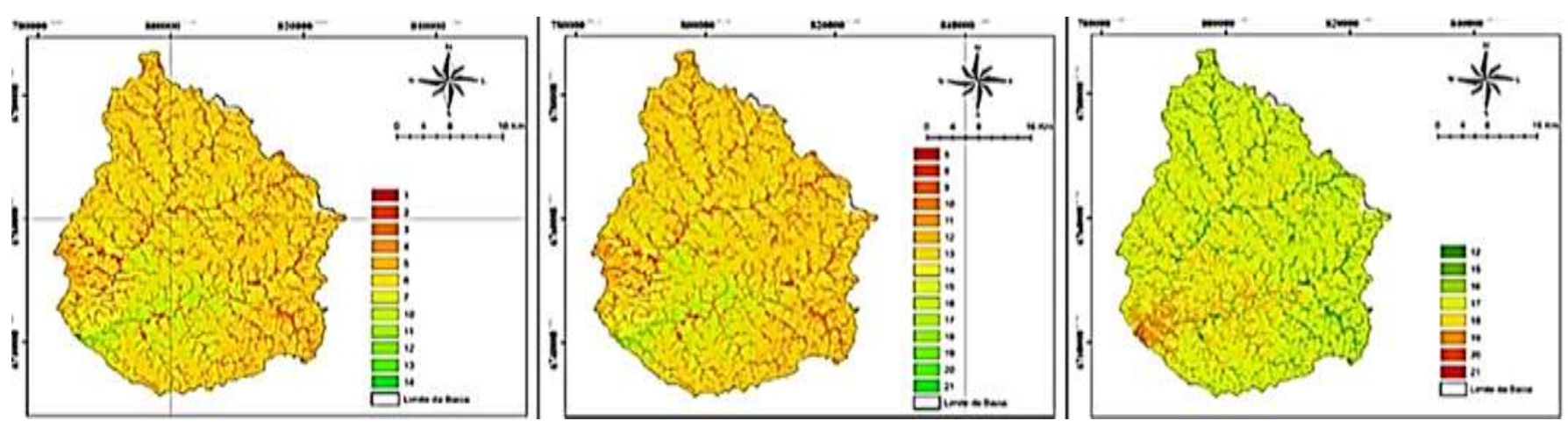

Fonte: Autores (2021).

Para o cenário 1, maior classe de fragilidade em tamanho de área de abrangência está representado pela Classe 5, cruzamento dos dados de PPS da Classe $3\left(10-50\right.$ ton.ha ${ }^{-1}$.ano $\left.{ }^{-1}\right)$ e os dados do BHC para chuvas mínimas da Classe $1(<0$ $\mathrm{mm}$ ). A classe 5 de fragilidade representa o quinto maior valor de fragilidade para a Bacia Cachoeira Cinco Veados, RS. A maior área de abrangência desta classe justifica-se por ser a classe de PPS que compreende maior área da bacia. A classe de fragilidade com menor área representada quando considerado o BHC para chuvas mínimas foi a Classe 14, com 17 hectares de área, nas proximidades do exutório da bacia hidrográfica.

Em áreas onde a demanda por água está acima da quantidade disponível, trabalha-se com culturas com menor exigência, ou que conseguem uma maior eficiência no uso da água, como é o caso da cultura de eucalipto. Apesar da demanda de água ser maior, em função da maior produção de biomassa quando comparado a uma cultura agrícola, a cultura de eucalipto possui mecanismos fisiológicos que reduzem a transpiração, reduzindo a área foliar em locais de maior déficit hídrico (Reis, 2018; 
Xavier et al., 2018).

O cenário 2 de planejamento ambiental do uso do solo considerou anos normais, ou seja, anos com chuvas médias, onde foram geradas 15 classes de fragilidade (Figura 6), sendo que para este cenário a Classe 1 do BHC é quase insignificante, ou seja, não há déficit hídrico.

A classe 13 de fragilidade representa em torno de 55,5\% da área total da bacia, e está associada a PPS da classe 2 ( 1 10 ton.ha $^{-1} \cdot$ ano $\left.^{-1}\right)$ e a classe 2 do BHC $(0-5 \mathrm{~mm})$, conforme Tabela 3. A classe de fragilidade 19 é mais abrangente e a classe de fragilidade 11 é a menos abrangente considerando BHC médio, com área de 86.016 e 1 hectares, respectivamente.

Considerando chuvas máximas para o balanço hídrico climatológico, observa-se que as classes de fragilidade têm uma redução da criticidade (Figura 6).

Tal resultado aponta que a maior criticidade da Bacia ocorre em anos com chuvas mínimas e médias (anos secos e normais) quando comparada aos anos chuvosos. Evidencia-se que, em anos chuvosos, mesmo apresentando uma maior criticidade em relação a PPS por erosão hídrica, ainda assim as áreas são menos suscetíveis a fragilidades quando analisado em conjunto com a variável BHC.

Observa-se que todas as classes de fragilidade estão na Classe 3 do BHC, que aponta para chuvas acima de $114 \mathrm{~mm}$, considerada chuva mínima em anos chuvosos. Ainda na Tabela 3 verificam-se as áreas por classe de fragilidade (USLE e BHC (Máx.)).

A Classe 17 de fragilidade abrange o maior percentual de área da Bacia Cachoeira Cinco Veados, RS, para chuvas máximas, e considera PPS da Classe $5\left(100-500\right.$ ton.ha $^{-1}$.ano $\left.{ }^{-1}\right)$ e BHC da Classe 3 (> $\left.5 \mathrm{~mm}\right)$, com 91.437 hectares, sendo que a menor classe (Classe 16) abrange somente 1 hectare.

Para o planejamento ambiental de uma área, por exemplo, para implantação de uma cultura, seja florestal ou agrícola, é necessário ter conhecimento da disponibilidade de água no solo e da PPS para o local, de acordo com dados históricos médios (Pinto et al., 2016; De Souza et al., 2017).

Quando se trata de culturas agrícolas, deve-se atentar para períodos críticos, ou seja, quando os valores do BHC atingem valores abaixo da capacidade de água disponível, estágio em que a planta não consegue mais retirar água do solo, ocasionando perdas na produção (Sanches et al., 2015; Sanches et al, 2017).

Para culturas florestais, cujas raízes são capazes de buscar água nas camadas mais profundas do solo, os valores críticos do BHC devem ser observados com maior atenção no período de implantação e estabelecimento da cultura, considerando os três primeiros meses após o plantio das mudas no campo (Santos, 2018; Voltolini et al., 2018).

Estabelecer uma relação entre a demanda de água por uma cultura e a disponibilidade de água no solo contribui no prognóstico do potencial produtivo dos plantios florestais, considerando as determinadas condições climáticas às quais a cultura está exposta na região onde é feito seu cultivo, fatores estes determinantes na produtividade e na duração do ciclo (De Souza et al., 2020). Para a cultura do eucalipto, por exemplo, destaca-se a necessidade de irrigação na fase de plantio, que comumente utiliza-se polímeros hidroretentores (hidrogel), reduzindo o número e volume de irrigações (Sousa et al., 2013).

Para longos períodos de falta de água disponível no solo, as culturas agrícolas ficam mais suscetíveis quando comparadas as culturas florestais, em função de as mesmas possuírem raízes superficiais e serem plantas de ciclo curto (Maeda \& Medrado, 2017). O período de floração e formação de frutos para uma cultura agrícola varia, geralmente de 15 a 30 dias, ou seja, a não disponibilidade de água neste período pode ocasionar a perda total ou parcial da produção (Bilibio et al., 2010).

As atividades desenvolvidas na bacia estudo de caso são essencialmente agrícolas, sendo que as propriedades variam entre pequenas e médias, produzindo principalmente soja, trigo, milho, cevada, aveia, entre outras. $\mathrm{O}$ uso intenso das atividades agrícolas reflete diretamente na conservação da biodiversidade local, restando poucos remanescentes de ecossistemas naturais. Alguns municípios possuem áreas de silvicultura, normalmente associadas à cultura de fumo. 
Considerando a PPS, por ordem de maiores perdas têm-se: uso campestre $\left(3.211,49\right.$ ton.ha ${ }^{-1} \cdot$ ano $\left.^{-1}\right)$, uso floresta/reflorestamento $\left(1 \cdot 267,54\right.$ ton.ha ${ }^{-1} \cdot$ ano $\left.^{-1}\right)$ e uso agropecuária $\left(600,82\right.$ ton.ha ${ }^{-1} \cdot$ ano $\left.^{-1}\right)$.

$\mathrm{O}$ uso antrópico urbano foi desconsiderado por ser área já consolidada. Tais dados indicam que, toda a área ocupada por uso campestre, é passível dos outros usos, pois as perdas potenciais são menores. As áreas que estão ocupadas por floresta/reflorestamento são passíveis de uso com agropecuária, que é o uso de menor impacto quando considerada a PPS, determinada pela Equação Universal de Perda de Solo.

Tendo como base o tamanho das propriedades em geral da bacia analisada, variando de pequenas à médias, aponta-se que as áreas ocupadas pelo uso campestre são passíveis de uso com floresta/reflorestamento, respeitando o limite percentual para a unidade de paisagem, uma vez que se encontra dentro dos limites de PPS aceitável e estão de acordo com o Zoneamento Ambiental da Silvicultura.

O uso com floresta/reflorestamento, que compreendem as áreas de silvicultura (florestas plantadas), soma 46,38 $\mathrm{km}^{2}$ (4.638 ha), representando $3 \%$ da área total da bacia $\left(1.541,9 \mathrm{~km}^{2}\right)$.

O Zoneamento Ambiental da Silvicultura do Rio Grande do Sul aponta que a Unidade de Paisagem PM9, na qual está inserida a Bacia Hidrográfica Ibicuí, representada pela sigla U50, comporta um percentual máximo para silvicultura de 10,8\%, com maciços florestais de tamanho máximo 16 km² (1.600 ha) e uma distância mínima entre maciços de 1,4 km. A partir dessas informações é possível afirmar que novas áreas da Bacia estudo de caso Cachoeira Cinco Veados, RS, podem ser convertidas em áreas de silvicultura.

$\mathrm{Na}$ Figura 7 observam-se as áreas já cobertas pelo uso floresta/reflorestamento, representada pela cor verde escuro. Na cor verde claro, estão representadas as áreas que são passíveis de uso floresta/reflorestamento $\left(486,7 \mathrm{~km}^{2}\right)$, dentro dos limites de PPS já estabelecidas. Porém, se toda a área passível de uso com floresta/reflorestamento for utilizada para este fim, excede o limite estabelecido pelo Zoneamento Ambiental da Silvicultura no RS, que é de 10,8\% para esta unidade de paisagem.

Figura 7: Áreas com uso floresta/reflorestamento e passíveis deste uso.

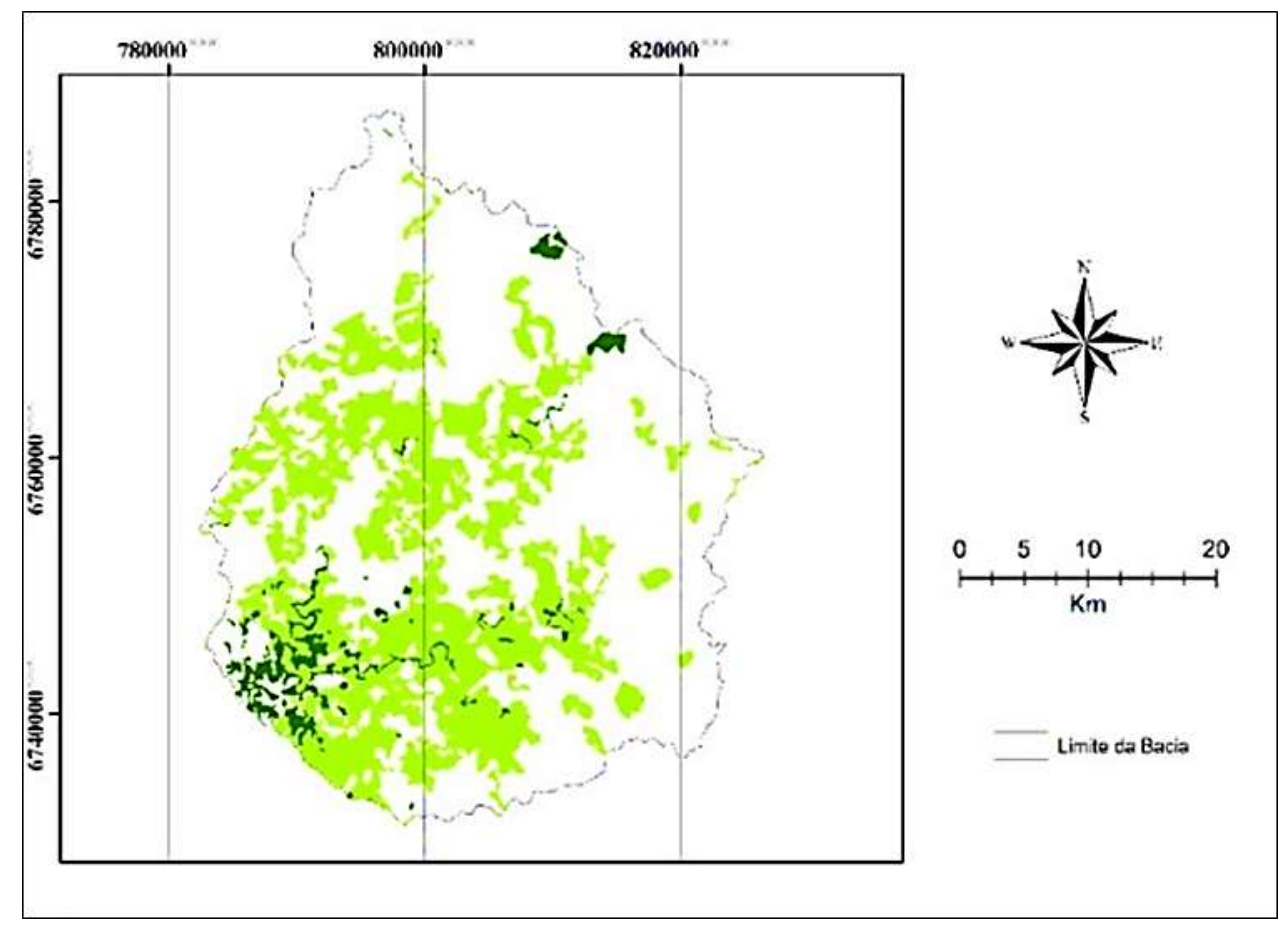

Fonte: Autores (2021). 
Ressalta-se a importância das florestas plantadas, mesmo em pequenas propriedades, pois pode contribuir como renda extra, além de outras funções, como: diminuição da pressão sobre florestas nativas; reaproveitamento de áreas degradadas pela agricultura; sequestro de carbono; proteção do solo e da água (Ribeiro et al., 2018). Em áreas adjacentes a florestas nativas, ou mesmo a outros plantios florestais, podem servir como corredor ecológico para a fauna local.

\section{Considerações Finais}

O arranjo metodológico baseado na PPS por erosão hídrica e BHC para a Bacia Cachoeira Cinco Veados - RS, foi capaz de apontar áreas de criticidade e ainda quais fatores têm maior influência para determinar a criticidade da área de estudo, demonstrando potencial para fornecer subsídios para a tomada de decisão e planejamento ambiental do uso e ocupação do solo. Em relação a identificação de áreas mais críticas, o arranjo metodológico empregado permitiu elencar as necessidades de estudos mais aprofundados da bacia em relação as condições apresentadas atualmente e a cenarização das situações criadas com a mudança da cobertura do solo, levando em consideração as variáveis climatológicas.

A metodologia utilizada para o planejamento ambiental do uso do solo da Bacia estudo de caso Cachoeira Cinco Veados, RS, poderá ser empregada em outras bacias e áreas de estudo, considerando que a bacia estudada foi a área de teste. O aperfeiçoamento dos métodos utilizados leva em consideração os dados de entrada e a confiabilidade dos mesmos.

O planejamento ambiental, baseado em PPS por erosão e BHC, refletiu uma situação real de grande parte das bacias hidrográficas da região sul do Brasil, cujas estações do ano são bem definidas, com chuvas regulares.

Ainda, observa-se que a Gestão Ambiental carece de um conjunto de áreas integradas que faça parte de uma política mais ampla, sendo necessário propiciar um rumo mais convergente para a implantação de um projeto de desenvolvimento sustentável, primeiramente a nível de bacias hidrográficas, com objetivos claros de um desenvolvimento econômico baseado na melhoria progressiva das condições sociais e a adoção de políticas de preservação, conservação e recuperação ambiental, tendo como premissa a implementação de zoneamento.

\section{Referências}

Bilibio, C., Carvalho, J. A., Martins, M., Rezende, F. C., Freitas, E. A., \& Gomes, L. A. (2010). Desenvolvimento vegetativo e produtivo da berinjela submetida a diferentes tensões de água no solo. Revista Brasileira de Engenharia Agrícola e Ambiental - Agriambi, 14(7), 730-735. https://doi.org/10.1590/S141543662010000700007

Carvalho Neto, R. M. (2011). Uso do balanço hídrico climatológico para subsidiar tomadas de decisão quanto ao manejo de bacias hidrográficas. 2011. 90p. Dissertação (Mestrado) - Universidade Federal de Santa Maria, Santa Maria. https://repositorio.ufsm.br/handle/1/7776

Ceconi, D. E., Piccilli, D. G. A., Bernardi, F., \& Fensterseifer, P. (2018). Análise de vulnerabilidade visando o planejamento ambiental em bacia de captação para abastecimento público. Ambiente \& Sociedade, 21, 1-22. https://doi.org/10.1590/1809-4422asoc0078r2vu18L1AO

Costa, L. R. F., Oliveira, V. P. V., \& Santos, J. (2019). O. Fragilidade ambiental no contexto de sítio urbano na sub-bacia hidrográfica do Rio Banabuiú-Ceará. Revista Brasileira de Geografia Física, 12(7), 2580-2594, http://dx.doi.org/10.26848/rbgf.v12.7.p2580-2594.

De Faria, A. O. C. (2010). O zoneamento ambiental da silvicultura do rio grande do sul. Principais atores e uma perspectiva jurídico-institucional. Revista de Gestão Social e Ambiental 4(2), 118-137. https://doi.org/10.24857/rgsa.v4i2.273

De Souza, F. M., Lima, E. C. S., Da Silva Sá, F. V., Souto, L. S., Araújo, J. E. S., \& De Paiva, E. P. (2017). Crescimento inicial do milho sob doses de esterco caprino e disponibilidade de água no solo. Revista Verde de Agroecologia e Desenvolvimento Sustentável, $12(2), 241-245$. https://dialnet.unirioja.es/servlet/articulo?codigo=7106877

De Souza, R. G. T., Liarte, G. V. C. C., De Lima, R. B., \& De Abreu, J. C. (2020). Classificação de sítios em plantio florestal de eucalipto no estado do Amapá. Revista Arquivos Científicos (IMMES), 3(1), 106-110. https://doi.org/10.5935/2595-4407/rac.immes.v3n1p106-110

Dos Santos Andrade, L. R., Araújo, S. M. S., De Souza Andrade, M. Z. S., \& Medeiros, L. E. L. (2018). Degradação ambiental no Açude de Bodocongó na cidade de Campina Grande, Paraíba. Revista Verde de Agroecologia e Desenvolvimento Sustentável, 13(1), 74-83. https://editoraverde.org/gvaa.com.br/revista/index.php/RVADS/article/view/5377

Guimarães, N. D. F., Gallo, A. D. S., Fontanetti, A., Meneghin, S. P., De Souza, M. D., Morinigo, K. P., \& Silva, R. F. D. (2017). Biomassa e atividade microbiana do solo em diferentes sistemas de cultivo do cafeeiro. Revista de Ciências Agrárias, 40(1), 34-44. https://doi.org/10.19084/RCA16041

Maeda, S.; \& Medrado, M. J. S. (2017). Plantações florestais comerciais e o solo. Embrapa Florestas-Capítulo em livro científico (ALICE). 
Pereira, M. D. R. P., \& De Cristo, S. S. V. (2019). Análise morfopedológica da bacia hidrográfica do ribeirão Taquaruçu Grande, Palmas-Tocantins. Revista Interface (Porto Nacional), 17(17), 44-58. https://sistemas.uft.edu.br/periodicos/index.php/interface/article/view/7872

Pinheiro, M. R., Costa, J. R., Scigliano, B. F., Ferreira, R. P. D., Cianfarra, P., \& Manfredini, S. (2020). Interações solo, relevo e material de origem na região do Alto Estrutural do Pau d'Alho-sudeste do Brasil. Revista do Instituto Geológico, 41(1), 49-67.

http://dx.doi.org/10.33958/revig.v41i1.686

Pereira, A. S., Shitsuka, D. M., \& Pereira, F. J., S, R. (2018) Metodologia do trabalho científico. Santa Maria: UAB / NTE / UFSM. https://repositorio.ufsm.br/handle/1/15824?show=full

Pinto, M. A. B., Parfitt, J. M. B., Timm, L. C., Faria, L. C., \& Scivittaro, W. B. (2016). Produtividade de arroz irrigado por aspersão em terras baixas em função da disponibilidade de água e de atributos do solo. Pesquisa Agropecuária Brasileira, 51(9), 1584-1593. https://doi.org/10.1590/S0100-204X2016000900058

Python Software Foundation. 2017. Python Language Reference. Versão 2.7. <http://www.python.org>.

Reis, L. A. C. (2018). Identificação de características fisiológicas relacionadas à tolerância ao déficit hídrico em clones comerciais de Eucalyptus spp. e Corymbia spp. 145 f. Tese (Doutorado em Fisiologia Vegetal) - Universidade Federal de Viçosa, https://www.locus.ufv.br/handle/123456789/27568

Ribeiro, K. V., \& Albuquerque, E. L. S. (2017). Sistemas ambientais no alto curso da Bacia Hidrográfica do Rio Poti, estado do Ceará. Revista Equador, 6(1), 57-73. https://revistas.ufpi.br/index.php/equador/article/view/5734

Ribeiro, F. T., Ribeiro, M. E. O., Antoniolli, B. I., Da Silva, J. M. S., \& De Farias Venturin, E. V. (2018). Os Sistemas Florestais na Preservação das APP. Revista de Psicologia, 12(39), 300-316. https://doi.org/10.14295/idonline.v12i39.992

Sanches, A. C., Gomes, E. P., Rickli, M. E., fasolin, J. P., Soares, M. R., \& De Goes, R. H. (2015). Produtividade e valor nutritivo do capim Tifton 85 irrigado e sobressemeado com aveia. Revista Brasileira de Engenharia Agrícola e Ambiental-Agriambi, 19(2), 126-133. https://doi.org/10.1590/18071929/agriambi.v19n2p126-133

Sanches, A. C., Gomes, E. P., Rickli, M. E., Friske, E., \& Fasolin, J. P. (2017). Productivity and nutritive value of Tifton 85 in summer, with and without irrigation under different nitrogen doses. Engenharia Agrícola, 37(2), 246-256. https://doi.org/10.1590/1809-4430-Eng.Agric.v37n2p246-256/2017

Santos, F. D. D. Construção de um índice de fragilidade baseado na perda de solo e balanço hídrico climatológico. 2018. 125p. Dissertação (Mestrado em Engenharia Florestal), Universidade Federal de Santa Maria, Santa Maria, RS. https://repositorio.ufsm.br/handle/1/14757

Saraiva, V. I. C., Da Silva, A. S., \& Dos Santos, J. P. C. (2016). Uso do mapa de solos como subsidio para definição de áreas de suscetibilidade à erosão na bacia hidrográfica São João, Lagos e Una. Geo UERJ, n. 29, 354-373. https://doi.org/10.12957/geouerj.2016.19660

Sousa, G. T. O., De Azevedo, G. B., \& Luduvico, J. R. (2013). Incorporação de polímero hidroretentor no substrato de produção de mudas de Anadenanthera peregrina (L.) Speg. Enciclopédia Biosfera, 9(16), 1270-1278. http://www.conhecer.org.br/enciclop/2013a/agrarias/incorporacao\%20de\%20polimero.pdf

Thornthwaite, C. W., \& Mather, J. R. (1995). The water balance: publications in climatology. 104 p. New Jersey: Drexel Institute of Technology.

Voltolini, L. C., Mercadante, M. E. G., Ramos-Filho, L. O., Moriconi, W., \& De Queiroga, J. L. (2018). Uso da Água em Sistemas Agroflorestais. Cadernos de Agroecologia, 13(2), 1-10. http://cadernos.aba-agroecologia.org.br/index.php/cadernos/article/view/2374

Xavier, T. M. T., Pezzopane, J. E. M., Penchel, R. M., \& Pezzopane, J. R. M. (2018). Uso de fotoprotetor foliar em mudas de eucalipto em condição de deficit hídrico. Revista Brasileira de Agricultura Irrigada, 12(2), 2418-2429. https://www.alice.cnptia.embrapa.br/handle/doc/1097024

Weiler, E. B. (2017). Indicadores de perda de solo espacializados como ferramenta de apoio à decisão para gestão ambiental integrada de bacias hidrográficas. 133p. Dissertação (Mestrado em Engenharia Florestal), Universidade Federal de Santa Maria, Santa Maria, RS. https://repositorio.ufsm.br/handle/1/12836

Wischmeier, W. H., \& Smith, D. D. (1978). Predicting rainfall erosion losses - a guide to conservation planning. Washignton, USDA. 58p. (Agricultural Handboo, 537).

Wolschick, N. H., Barbosa, F. T., Bertol, I., Dos Santos, K. F., De Souza Werner, R., \& Bagio, B. (2016). Cobertura do solo, produção de biomassa e acúmulo de nutrientes por plantas de cobertura. Revista de Ciências Agroveterinárias15(2), 134-143. https://doi.org/10.5965/223811711522016134 